\title{
СЭР БЕРНАРД ПЭРС И ШКОЛА СЛАВЯНСКИХ ИССЛЕДОВАНИЙ В ЛОНДОНЕ
}

В начале любого большого и перспективного дела - ещё до того как это дело становится большим и перспективным - находятся, как правило, энтузиасты-одиночки. Именно таким был сэр Бернард Пэрс (Pares, 1867-1949), один из «пионеров» британского россиеведения. Выходец из состоятельной семьи, выпускник Тринити-колледжа, он в первые годы после окончания университета работал школьным учителем и не помышлял о России. Получив наследство, Пэрс бросил преподавание и какое-то время путешествовал по Европе, исследуя места сражений и маршруты походов Наполеона Бонапарта. Неизвестно точно, что побудило его обратиться к русской истории и культуре, - то ли интерес к наполеоновским войнам и нашествию Наполеона на Россию, то ли вышедшая в 1877 г. книга Дональда Маккензи Уоллеса Россия, а возможно, и иные обстоятельства. Во всяком случае, Пэрс посетил впервые Россию в 1898 г. и с тех пор стал её горячим поклонником. Он довольно быстро овладел русским языком, хотя и говорил на нём до конца жизни с «чудовищным акцентом». «Впрочем, с таким акцентом он говорил на всех известных ему иностранных языках», - вспоминала секретарь Пэрса Дороти Гэлтон (“Some Notes" 1).

АндРей АнАтольЕвич НЕкРАСов - доцент канд. ист. наук, Ярославский государственный университет, Исторический факультет, Кафедра новейшей отечественной истории, Ярославль, Россия; e-mail: nekandr@yahoo.com; ORCID: https://orcid.org/0000-0003-3587-5416.

AndRei NeKrasov - doktor historii, docent (kandydat nauk), Jarosławski Uniwersytet Państwowy, Wydział Historyczny, Katedra Nowożytnej Historii Rosji, Jarosław, Rosja; e-mail: nekandr@yahoo.com; ORCID: https://orcid.org/0000-0003-3587-5416.

ANDREI NeKrasov - PhD in History, Docent (Candidate of Sciences), Yaroslavl State University, Faculty of History, Chair of Modern Russian History, Yaroslavl, Russia; e-mail: nekandr@ yahoo.com; ORCID: https://orcid.org/0000-0003-3587-5416. 
Начиная с 1904 г., Пэрс регулярно ездил в Россию, а с 1906 г., пожалуй, проводил в России больше времени, чем в Великобритании. Придерживаясь либеральных политических взглядов, он довольно быстро сблизился с деятелями российского либерального движения - И. Петрункевичем, А. Гучковым и другими, приветствовал учреждение в России Государственной Думы, рассчитывая на превращение России в недалёком будущем в развитое демократическое государство. Пэрс неоднократно посещал думские заседания, собрания кадетов и октябристов, а в 1909 г. организовал визит большой делегации депутатов Думы в Великобританию. В 1912 г. последовал ответный визит британских парламентариев в Россию, на этот раз по инициативе британского МИДа, но при активном содействии Пэрса. Пэрс полагал, что Великобритания и Россия являются естественными союзниками, но для укрепления этого союза необходимо склонить британское общественное мнение на сторону России. Добиться этого можно было, по его мнению, путём создания англо-российских общественных организаций, развития культурного обмена и максимального распространения в Великобритании информации о России и русской культуре.

С началом Первой мировой войны Пэрс был направлен в Россию британским министерством иностранных дел в качестве наблюдателя в действующую армию, а впоследствии стал военным обозревателем газеты Дейли телеграф. Свои военные впечатления он позднее отразил в книге День за днём с русской армией (Pares, Day by Day).

Большинство коллег Б. Пэрса скептически относились к его прогнозам о трансформации Российской империи в недалёком будущем в динамично развивающееся демократическое государство. Тем не менее, история, казалось, подтверждала правоту Пэрса: в России произошла демократическая революция, император отрекся от престола, было сформировано правительство, в составе которого Пэрс с удивлением обнаружил немало своих русских друзей и единомышленников. Так, семь из двенадцати министров первого состава Временного правительства оказались в прошлом постоянными корреспондентами издававшегося Пэрсом в Ливерпуле в 1912-1914 гг. журнала The Russian Review (Pares, A Wandering Student 100). Пэрс понимал, что в России происходят события исторического, возможно, даже всемирно-исторического значения, и не мог упустить случая оказаться непосредственным свидетелем этих событий, а возможно, и поучаствовать в них. 
Пэрс неоднократно подчёркивал свою «беспартийность» и старался наладить диалог с представителями любых политических партий, которые стояли на патриотических позициях и выступали против сепаратного мира с Германией, от октябристов до меньшевиков. Естественно, его отношение к Ленину и большевикам было откровенно враждебным. В течение весны и лета 1917 г. он в качестве сотрудника британского посольства разъезжал по стране, выступая в воинских частях с разъяснениями политики Великобритании по отношению к России и убеждая солдат и офицеров в необходимости сохранения антигерманской коалиции. В июне 1917 г. он каким-то непостижимым для него самого образом оказался в составе Всероссийского центрального комитета по организации добровольческой революционной армии (ВЦК ДРА) (Pares, A Wandering Student 253). По заданию Комитета он отправился в Британию, чтобы получить для добровольческой армии оружие и боеприпасы, но, добравшись до Швеции, узнал о корниловском мятеже и роспуске Комитета.

В очередной раз Пэрс оказался в России в январе 1919 г. в качестве официального представителя Великобритании в армии Колчака. Миссия его была не вполне определённой. Его главной задачей было чтение лекций для местного населения, по три лекции в каждом населённом пункте, включая и неизменно вызывавшую недоумение Пэрса лекцию по истории лейбористской партии Великобритании. В то же время, эти публичные выступления позволяли ему пообщаться с представителями различных социальных групп и выяснить отношение населения к армии Колчака и представителям британского правительства (Pares, $A$ Wandering Student 258). По-видимому, главный смысл миссии Пэрса заключался не только в разъяснении роли западных союзников в российской гражданской войне, но и в укреплении авторитета Колчака и его армии у местного населения.

Возникает правомерный вопрос: как мог либерал и джентльмен Бернард Пэрс сотрудничать с такой противоречивой фигурой, как адмирал Колчак? В своих воспоминаниях Пэрс старается всячески обойти вопрос о «белом терроре». Лишь единожды он глухо упоминает о своём докладе Колчаку с протестом против расстрела заложников «одним из его генералов» (A Wandering Student 262). Более откровенен он в своей рецензии на книгу Допрос Колчака, изданную в 1925 г. под редакцией К.А. Попова. Пэрс старается максимально оправдать Колчака, подчёркивая на его боевые и научные заслуги. По мнению Пэрса, Колчак никогда не стремился к единоличной власти и готов был в любой момент 
передать власть законно избранному правительству. Отметая обвинения Колчака в чрезмерной жестокости, Пэрс пишет, что адмирал не мог нести ответственность за расстрел восьми членов Учредительного Собрания в Омске в декабре 1918 года, ибо он находился в это время чуть ли не при смерти из-за тяжёлой формы пневмонии и не мог отдавать каких-либо распоряжений. Особо он отмечает реакцию Колчака на свой доклад о расстреле заложников генералом Розановым в Красноярске. Колчак не только немедленно отстранил генерала от командования, но и издал приказ, категорически запрещавший повторение подобных эксцессов. К сожалению, пишет Пэрс, приводя в пример атаманов Калмыкова и Семёнова, не всегда распоряжения Верховного выполнялись, поэтому несправедливо было бы возлагать на него вину за действия его подчинённых (“Dopros Kolchaka” 229). Пэрс, защищая доброе имя адмирала, ссылается даже на слова Ленина:

Довольно неумно порицать Колчака только за то, что он насильничал над рабочими и даже порол учительниц за то, что они сочувствовали большевикам. Это вульгарная защита демократии, это глупые обвинения Колчака. Колчак действует теми способами, которые он находит. (Ленин 355; “Dopros Kolchaka" 230)

Завершает Пэрс свою рецензию фразой: «Честь и слава великому человеку и истинному русскому патриоту» («Dopros Kolchaka» 230).

Пэрс был крайне разочарован крахом британской политики в России. «Британская интервенция закончилась полным провалом», - писал он в своих воспоминаниях. - В России мы отстаивали наши конституционные принципы; образованные классы России были на нашей стороне и рассчитывали на нашу помощь, - тем не менее, мы пытались силой насаждать наши принципы. Это вмешательство, необоснованное и бесполезное, окончательно утратило смысл после 11 ноября 1918 г., когда Германия проиграла войну. Я всегда был противником мировой революции, то есть, навязывания чуждых идей моей собственной стране. Но это ведь именно то, чем я сам занимался в России» (A Wandering Student 269). И всё же ему не за что было себя укорять, он лично делал всё, что было в его силах, для укрепления российско-британских связей. Его заслуги были высоко оценены как в России, так и в Британии. Пэрс был награждён в 1919 г. Орденом Британской Империи и возведён в рыцарское достоинство; ранее он получил несколько наград от российского правительства, самой ценной из которых был Георгиевский крест. 
В октябре 1919 г. Б. Пэрс вернулся в Великобританию, и на этом его военная и политическая деятельность завершилась. Он мог теперь вернуться к главному делу своей жизни - преподаванию русской истории и распространению знаний о России и русской культуре в британском обществе. Пэрс был буквально одержим Россией, непременно сводя к ней разговор с любым собеседником, о чём бы изначально ни заходила речь. Американский славист Сэмюэл Харпер, приехав в 1911 г. по приглашению Пэрса преподавать русский язык и право в Школе россиеведения при Ливерпульском университете, сразу же получил совет «ни в коем случае в беседах с Пэрсом не затрагивать тему России, иначе его невозможно будет остановить» (Harper 74). Согласно воспоминаниям Д. Гэлтон, «разговорами о России он мог утомить кого угодно» ("Some Notes" 2).

Когда британский историк и политический активист Роберт СетонУотсон в марте 1915 г. поделился с главой Королевского колледжа Лондонского университета Р. Берроузом своей идеей о создании специальной Школы славянских исследований, на должность директора Школы он предложил Бернарда Пэрса. Действительно, лучшей кандидатуры найти было невозможно. Пэрс хорошо знал русскую историю и культуру, накопил определённый политический и административный опыт, имел обширные связи в российских и британских политических кругах и обладал всеми необходимыми качествами руководителя: способностью принимать решения, твёрдым характером (Д. Гэлтон называла его «доброжелательным автократом»), энергичностью и пунктуальностью. Пэрс с радостью принял предложение, но не смог сразу занять директорский пост, так как находился на службе и должен был немедленно вернуться в Россию.

Пэрс и сам мечтал о создании подобного учебного и научно-просветительского центра. Правда, его интересовала преимущественно Россия, а не история славянства в целом. Он опасался, что российская история и культура растворится в общеславянских исследованиях. В 1907 г. Он основал при Ливерпульском университете первую в Великобритании Школу россиеведения (подробнее о Школе россиеведения см.: Трибунский, «Становление Школы россиеведения»; Трибунский, «Преподавание и изучение экономики России»).

Правда, этот опыт не вполне удался. Британское общество в целом почти не интересовалось Россией, в большинстве британских школ русский язык не преподавался, поэтому сложно было найти для Школы 
и потенциальных студентов, и квалифицированных преподавателей. Те немногие специалисты по русскому языку и литературе, которые имелись в Великобритании, были уже задействованы в Кембридже и Оксфорде. Пэрсу пришлось приглашать преподавателей из-за рубежа: С. Харпер из Чикагского университета преподавал историю российского государства и права, приглашённые по рекомендации П.Б. Струве из России выпускники Санкт-Петербургского политехнического института В.Ф. Гефдинг и А.Я. Бабков читали лекции по российской экономике, русский язык и литературу преподавал русский эмигрант М.В. Трофимов.

После Второй мировой войны в ряде американских университетов широкое распространение получила программа «региональных исследований» (area studies), ориентированная на подготовку специалистов по различным регионам Европы, Азии и Латинской Америки, которые за относительно короткое время должны были освоить целый ряд учебных дисциплин: интенсивная языковая подготовка, география региона, история, экономика, политические и социальные институты, психология и антропология, наряду с общими курсами, такими, например, как основы дипломатии. Однако, идея эта появилась гораздо раньше, и не в США, а в Великобритании. Именно Бернард Пэрс и его коллеги последовательно выступали против сведения российских и славянских исследований к изучению языка и литературы, как это было принято в Кембридже и Оксфорде. Поэтому в качестве базы для развёртывания комплексного изучения России, её культуры, истории, экономики, географии, и был избран один из новых британских университетов Ливерпульский, поскольку традиционные университеты были слишком консервативны и крайне неохотно вносили изменения в учебные программы.

Неслучайно Д. Гэлтон, ревниво оберегавшая престиж Пэрса и Школы славянских и восточноевропейских исследований, в короткой рецензии на мемуары известного американского специалиста по России Джона Хазарда решительно отстаивала приоритет Великобритании в разработке программы региональных исследований (regional studies):

Эта идея - использование языка в качестве инструмента для изучения страны во всех ее аспектах - была любимой у сэра Бернарда Пэрса, на ней основана была вся работа возглавляемой им Школы славянских исследований Лондонского университета. Он повсюду говорил об этом ещё до войны и, перебравшись в 1943 г. в Соединенные Штаты, он продолжал 
продвигать эту идею, посещая американские университеты. Он часто обсуждал вопрос о важности «региональных исследований» и в Лондоне, как с Дж. Маршаллом из Фонда Рокфеллера, предоставившего грант для открытия Русского института Колумбийского университета, и с профессором русской истории этого университета Ф. Мозли. Таким образом, «региональные исследования» в Великобритании начали развиваться задолго до того, как они достигли Америки, и обязаны они своим происхождением сэру Бернарду Пэрсу. (Galton, “Recollections” 612)

Официально об открытии Школы славянских исследований в Лондоне было объявлено 19 октября 1915 г., но в условиях войны и в отсутствии директора она не могла полноценно функционировать. Не было собственного помещения, постоянного преподавательского состава, долговременной программы развития Школы, скудным было её финансирование. Тем не менее, Сетон-Уотсон пытался обеспечить Школу квалифицированными кадрами. Он пригласил, имея в виду не только академические, но и политические цели, своего давнего друга Томаша Масарика, с фальшивым сербским паспортом скрывавшегося от австрийской полиции, преподавать чешский язык и литературу, профессоров Белградского университета Йована Квижича и Павле Поповича - в качестве преподавателей географии и этнографии Балканского полуострова, а также сербохорватского языка, сам Сетон-Уотсон читал лекции по истории Чехословакии, Венгрии и Балкан. Вскоре появилась возможность ввести в программу Школы изучение польского языка, который преподавал польский эмигрант Август Залески, в недалёком будущем - министр иностранных дел независимой Польши (Seton-Watson 367-371).

После войны Масарик, Попович и Залески вернулись на родину, а кадровый состав Школы пополнился новыми сотрудниками, в основном, выходцами из Чехословакии и Югославии. Чехословацкое и югославское правительства платили им зарплату, снимая, таким образом, часть финансового бремени со Школы славянских и восточноевропейских исследований. Все эти обстоятельства определили основные направления деятельности Школы - изучение и преподавание польского, сербского, чешского, венгерского и румынского языков и культуры этих стран. Впоследствии Пэрс до конца своего пребывания в должности директора Школы старался неукоснительно придерживаться этой системы финансирования: сотрудники из стран Центральной, Южной и Восточной Европы получали зарплату от своих правительств, в то время 
как собственные средства Школы шли на преподавание русского языка и изучение российской истории и культуры (Galton, «Some Notes» 4-5).

Вернувшись в 1919 г. из Сибири, Пэрс занял должность профессора Лондонского университета, а в 1922 г. - директора Школы славянских исследований (в 1928 г. переименована в Школу славянских и восточноевропейских исследований). В течение последующих двадцати лет он пытался добиться разделения этих должностей, но так и не преуспел в этом. Как директор он не получал никакого жалованья, живя лишь на профессорскую зарплату. Сам Пэрс в быту был неприхотлив, и денег ему хватало, но он беспокоился о своём потенциальном преемнике, которого вряд ли могло устроить такое положение дел.

О скромности Пэрса свидетельствует в своих записках Д. Гэлтон, проработавшая с ним бок о бок с 1928 до 1939 г.:

Он всегда выглядел довольно неопрятно, полагая, вероятно, что некоторая небрежность во внешнем виде должна быть присуща профессору; кроме того, в то время в его семье не было никого, кто мог бы о нем должным образом позаботиться. Карманы его пиджаков всё время были набиты старыми письмами и бумагами, которые через дырки проваливались под подкладку; нередко ему приходилось елозить рукой у себя за спиной, пытаясь нащупать документ, который был ему нужен в данный момент. Зимой и летом он неизменно носил калоши. (“Sir Bernard Pares and Slavonic Studies” 481).

Пэрса тяготила зависимость Школы от Королевского колледжа, и в течение многих лет он пытался от неё избавиться. Пока Школа была одним из подразделений колледжа, у Пэрса постоянно возникали конфликты с руководством колледжа, которое совершенно не было заинтересовано в расширении сферы российских и восточноевропейских исследований. Обрести статус автономного института в рамках Лондонского университета Школе удалось только в 1932 г., но тут же возникла новая проблема. Согласно правилам университета, подобные учреждения должны были называться институтами, Пэрс же настаивал на сохранении прежнего названия - Школа славянских и восточноевропейских исследований, поскольку статус школы был выше, чем статус института, хотя в действительности Школа никогда не являлась самостоятельным учреждением на правах колледжа. В конце концов, Пэрсу, хотя и с большим трудом, удалось настоять на своём, хоть это относилось исключительно к названию, а не статусу Школы (Galton, "Sir Bernard Pares and Slavonic Studies” 489). 
Пэрс оставался директором Школы до 1939 года, и все эти годы ему приходилось бороться за сохранение Школы, сталкиваясь одновременно с множеством финансовых и административных проблем, одна из которых неизменно порождала другую. Чтобы Школа могла нормально функционировать и обеспечивать осуществление наполеоновских планов Пэрса, необходимо было, во-первых, найти удобное и просторное помещение, в котором могли бы разместиться офисы сотрудников, аудитории, библиотека и какое-то общее пространство, где могли периодически собираться все сотрудники Школы и обсуждать текущие учебные и научные вопросы. Такое помещение появилось у Школы только в 1938 г., за год до отставки Пэрса и начала Второй мировой войны, но появилось оно не благодаря университету, а было построено на средства чехословацкого правительства, которое таким образом выражало свою благодарность Школе и персонально Сетон-Уотсону, много сделавшему для создания независимой Чехословакии. До этого Школа ютилась то в бывших армейских казармах, занимая там две комнаты, то в других, но столь же некомфортабельных и холодных помещениях.

Во-вторых, необходима была хорошая библиотека со штатным библиотекарем. Но не было ни удобного помещения для библиотеки, ни библиотекаря. В небольшой комнате, которая служила библиотекой, могли разместиться только справочные издания и периодика; книги в основном находились в офисах сотрудников, в соответствии со специализацией. Долгое время у Школы не было библиотекаря; на шесть часов в неделю по совместительству приходил сотрудник читального зала библиотеки Британского музея. Двери не запирались, поэтому многие книги постепенно исчезали в неизвестном направлении. Только в 1934 г., эмигрировав из нацистской Германии, библиотекарем в Школу устроился Сергей Якобсон, за короткое время сумевший каталогизировать все книги и периодические издания (Galton, "Sir Bernard Pares and Slavonic Studies" 490). В 1940 г. Якобсон уехал в США, где вскоре получил престижную работу в Библиотеке Конгресса.

Одной из главных проблем была постоянная нехватка денег, которая не позволяла должным образом пополнять библиотеку, а также расширять штат сотрудников и удерживать в Школе квалифицированных преподавателей. Лишь однажды, 1922 г. Школа славяноведения получила значительный грант от администрации университета $-£ 2000$. Это позволило несколько улучшить материальное положение Школы, расши- 
рить состав сотрудников, а часть средств была направлена на издание нового журнала - The Slavonic Review (Galton, "Some Notes" 5).

У Пэрса уже имелся к этому времени опыт издательской деятельности. В 1912-1914 гг. он, вместе с Г. Уильямсом и М. Бэрингом издавал в Ливерпуле журнал The Russian Review посвящённый «русской истории, политике, экономике и литературе». Журнал был скорее просветительским, нежели научным, и содержал материалы самой разной тематики: статьи по истории и географии России, экономические обзоры, фрагменты или полные тексты литературных произведений российских писателей и поэтов (как правило, в переводах Пэрса), статьи о русской литературе и фольклоре, народных обычаях, библиографические материалы. Цель журнала состояла в том, чтобы дать британскому читателю самое общее представление о России и ее культуре, так как Пэрс постоянно сетовал на полное невежество англичан в отношении России.

Той же линии придерживался и новый журнал - The Slavonic Review, - с той разницей, что материалы, в нём помещавшиеся, охватывали географически более широкий регион Восточной Европы, при этом публикаций, посвящённых России, было сравнительно мало. Польша, Венгрия или Чехословакия считались европейскими государствами и были ближе к Великобритании не только в географическом плане, но и в отношении культуры и религии, следовательно, вызывали гораздо больший интерес у британского читателя, чем «дикая» полуазиатская Россия. Даже русская революция мало что здесь изменила, поскольку «большевистская» Россия в глазах «цивилизованных» англичан стала еще более «дикой» и «азиатской». Поэтому не могло идти и речи об издании собственно «русского» журнала. Такой журнал начал издаваться намного позднее, с ноября 1941 г., в США, унаследовав название первого журнала Бернарда Пэрса - The Russian Review (об американском журнале The Russian Review см.: Некрасов).

Журнал The Slavonic Review издавался Пэрсом совместно с P.B. Ceтоном-Уотсоном. Среди сотрудников и авторов журнала были такие известные имена, как профессор русского языка и литературы Лондонского университета князь Д.П. Святополк-Мирский; историк, бывший член Государственной Думы от партии октябристов А.Ф.Мейендорф; британский бизнесмен Лесли Уркварт, предпринимательская деятельность которого была тесно связана с Россией, американские учёные С. Харпер и С.Х. Кросс. В сущности, журнал был международным, имел не только британского, но и американского редактора. В под- 
заголовке журнала было сказано, что он посвящен обзору «истории, экономики, филологии и литературы» славянских народов.

Содержание журнала было довольно эклектичным и не давало полноценной информации ни о русской истории, ни о современном положении России: во-первых, ощущался недостаток оригинальных статей, и объем журнала часто заполнялся случайными материалами; во-вторых, мешало отсутствие традиции изучения русской истории, специалистов, хорошо знающих русский язык; в-третьих, сказывалась труднодоступность документов и материалов по истории и экономике России, вследствие чего авторы из среды русских эмигрантов, преобладавшие численно, публиковали статьи по тем проблемам, в которых они хорошо ориентировались, занимаясь их исследованием еще с дореволюционных времен. К тому же, часть русских эмигрантов принципиально не хотела ничего писать о «большевистской» России, выражая тем самым свой протест. Безусловно, все это не способствовало получению читателями свежей и достоверной информации о том, что происходило в СССР.

В 1928 г. журнал сменил название на The Slavonic and East European Review. С течением времени американские авторы и издатели заняли в журнале преобладающие позиции, и с 1943 года журнал стал издаваться в США с подзаголовком Американская серия, сменив двумя годами позднее заглавие на American Slavonic and East European Review, а затем (в 1960 г.) на Slavic Review. Под этим названием он выходит в США до сих пор. В Великобритании же после войны было возобновлено издание журнала под прежним названием - The Slavonic and East European Review.

Помимо издания журнала, директорства в Школе славянских исследований и преподавательской работы, Б. Пэрс периодически публиковал книги и многочисленные статьи. Из книг Пэрса наибольшую известность приобрели многократно переиздававшаяся История России и Падение русской монархии (Pares, A History of Russia; Pares, The Fall). Кроме этого, его перу принадлежат две книги воспоминаний (My Russian Memoir; A Wandering Student), а также множество переводов русской литературной классики на английский язык. Среди его любимых произведений русской литературы были Горе om ума А.С. Грибоедова и басни И.А. Крылова, регулярно появлявшиеся на страницах The Slavonic Review. Также ему нравились рассказы Чехова, которого он предпочитал особо почитаемому западной публикой Толстому. В то же 
время, Пэрс недолюбливал многие сочинения русской классики за свойственный им пессимизм.

Подводя итог многогранной деятельности Бернарда Пэрса, можно сказать, что он сыграл в британском россиеведении и славяноведении не менее конструктивную роль, чем Арчибальд Кулидж или Джероид Робинсон - в американском. Те, кто его хорошо знал, в один голос называли его «миссионером», что создавало определённые неудобства для окружающих, так как он шёл к своей цели, по словам С. Харпера, «не считаясь с другими людьми». Но цель его была благородной, и он искренне любил Россию и русских людей. По словам Дороти Гэлтон, «его сердце и душа были отданы изучению России; в самом деле, он мог отождествлять себя с русскими настолько, что когда он иногда произносил слово «мы», собеседник вдруг понимал, что он имел в виду не себя и своих английских друзей, а русских» ("Sir Bernard Pares and Slavonic Studies" 482). Школа славянских и восточноевропейских исследований, которой Пэрс отдал двадцать лет жизни, существует до сих пор и является одним из крупнейших в Великобритании и за её пределами научных центров по изучению России и Восточной Европы (о развитии Школы в 1940-е - 1960-е гг. см.: Jopson; Rose; Bolsover).

\section{БИБЛИОГРАФИЯ}

Galton, Dorothy C. "Recollections of a Pioneering Sovietologist by John N. Hazard: Review". The Slavonic and East European Review, vol. 62, no. 4, 1984, pp. 611-612.

Galton, Dorothy C. "Some Notes for the History of the School of Slavonic Studies". School of Slavonic and East European Studies Library. University College London. Dorothy Galton Collection. GAL/1, pp. 1-21.

Galton, Dorothy. "Sir Bernard Pares and Slavonic Studies in London University, 1919-1939". The Slavonic and East European Review, vol. 46, no. 107, 1968, pp. 481-491.

Harper, Samuel N. The Russia I Believe In: The memoirs of Samuel N. Harper, 1902-1941. University of Chicago Press, 1945.

Jopson, Norman B., William J. Rose, \& George H. Bolsover. "The School of Slavonic and East European Studies: The First Fifty Years". The Slavonic and East European Review, vol. 44 , no. 102, 1966, pp. 1-30.

Lenin, Vladimir. "Rech' ob obmane naroda lozungami svobody i ravenstva 19 maya: I Vserossiyskiy s"yezd po vneshkol'nomu obrazovaniyu, 6-19 maya 1919 g." Polnoye sobraniye sochineniy, t. 38, Politizdat, 1974, ss. 333-372 [Ленин, Владимир. «Речь об обмане народа лозунгами свободы и равенства 19 мая: I Всероссийский съезд по внешкольному образованию, 6-19 мая 1919 г.» Полное собрание сочинений, т. 38. Политиздат, 1974, сс. 333-372]. 
Nekrasov, Andrei. “Zhurnal «The Russian Review» i yego rol' v stanovlenii sovetologii." Izvestiya Smolenskogo gosudarstvennogo universiteta, no. 2 (34), 2016, ss. 168-180 [Heкрасов, Андрей. «Журнал «The Russian Review» и его роль в становлении советологии». Известия Смоленского государственного университета, № 2 (34), 2016, cc. 168-180].

Pares, Bernard. "Dopros Kolchaka by K.A. Popov (Review)". The Slavonic and East European Review, vol. 22, no. 8, 1929, pp. 225-230.

Pares, Bernard. A History of Russia. Jonathan Cape, 1926.

Pares, Bernard. A Wandering Student: The Story of a Purpose. Syracuse University Press, 1948.

Pares, Bernard. Day by Day with the Russian Army, 1914-15. Constable \& Company Ltd., 1915.

Pares, Bernard. Moscow Admits a Critic. Thomas Nelson \& Sons, Ltd., 1936.

Pares, Bernard. My Russian Memoirs. Jonathan Cape, 1931.

Pares, Bernard. Russia and Reform. Archibald Constable \& Co. Ltd., 1907.

Pares, Bernard. Russia and the Peace. The Macmillan Company, 1945.

Pares, Bernard. The Fall of the Russian Monarchy: A Study of the Evidence. Jonathan Cape, 1939.

Roberts, Ian W. History of the School of Slavonic and East European Studies, 1915-1990. SSEES, 1991.

Seton-Watson, Robert W. "The Origins of the School of Slavonic Studies." The Slavonic and East European Review, vol. 17, no. 50, 1939, pp. 360-371.

Tribunskii, Pavel. "Prepodavaniye i izucheniye ekonomiki Rossii v Shkole rossiyevedeniya pri Liverpul'skom universitete". Izvestiya Smolenskogo gosudarstvennogo universiteta, no. 2 (34), 2016, сс. 188-193 [Трибунский, Павел. «Преподавание и изучение экономики России в Школе россиеведения при Ливерпульском университете». Известия Смоленского государственного университета, № 2(34), 2016, сс. 188-193].

Tribunskii, Pavel. "Stanovleniye shkoly rossiyevedeniya pri Liverpul'skom universitete i rossiyskoye nauchnoye zarubezh'ye". Russkoye zarubezh'ye i slavyanskiy mir: sbornik trudov. Slavisticheskoye obshchestvo Serbii, 2013, ss. 277-292 [Трибунский, Павел. «Становление школы россиеведения при Ливерпульском университете и российское научное зарубежье». Русское зарубежье и славянский мир: сборник трудов. Славистическое общество Сербии, 2013, сс. 277-292].

\section{SIR BERNARD PARES \\ I SZKOŁA STUDIÓW SŁOWIŃSKICH W LONDYNIE}

Streszczenie

W artykule omówiono różnorodne działania wybitnego brytyjskiego historyka Sir Bernarda Paresa na rzecz rozwoju studiów rosjoznawczych i słowianoznawczych w pierwszej połowie XX wieku. Pares był autorem kilku książek i wielu artykułów o Rosji, a także redaktorem czasopism The Russian Review i The Slavonic Review. Założył również pierwszą Szkołę Studiów Rosjoznawczych na Uniwersytecie w Liverpoolu (1907) i przez dwadzieścia lat był dyrektorem Szkoły Studiów Słowiańskich i Wschodnioeuropejskich na Uniwersytecie Londyńskim (1919-1939). Ze względu na jego zainteresowanie polityką, historią i kulturą Rosji, częste i długie wizyty w Rosji w latach 1906-1919 oraz bliską przyjaźń z wieloma rosyjskimi liberałami, nominację na oficjalnego obserwatora w armii rosyjskiej w 1915 r. i na przedstawiciela Wielkiej Brytanii 
w armii Kołczaka podczas wojny domowej, Pares stał się jednym z najbardziej szanowanych brytyjskich ekspertów spraw rosyjskich i słusznie objął stanowisko dyrektora Szkoły Slawistyki. Ten artykuł zwraca szczególną uwagę na różne problemy finansowe i administracyjne, z którymi borykał się Pares jako dyrektor szkoły. Autor konkluduje, że Bernard Pares był niezastąpionym ambasadorem wszystkiego, co rosyjskie, tłumaczem rosyjskiej poezji i prozy, badaczem historii Rosji oraz organizatorem studiów rosyjsko-słowiańskich w Wielkiej Brytanii.

Słowa kluczowe: Bernard Pares; The Slavonic Review; studia rosjoznawcze; Uniwersytet Londyński; historiografia brytyjska; ZSRR.

\section{SIR BERNARD PARES \\ AND THE SCHOOL OF SLAVONIC STUDIES IN LONDON}

Su m m a ry

This article covers the diverse activities of the renowned British historian Sir Bernard Pares on the development of Russian and Slavic studies in the first half of the 20th century. He was the author of several books and a fair number of articles on Russia, edited the journals The Russian Review and The Slavonic Review. Pares also founded the first School of Russian Studies at the University of Liverpool (1907) and served for twenty years as Director of the School of Slavonic and East European Studies at the University of London (1919-1939). Due to his interest in Russian politics, history and culture, frequent and lengthy visits to Russia from 1906 to 1919 and close friendship with many Russian liberals, his appointment as an official observer to the Russian army in 1915 and as a British representative to Kolchak's army during the Civil War, Pares became one of the most authoritative British experts on Russia and rightfully assumed the position of Director of the School of Slavonic Studies. This article pays close attention to various financial and administrative problems that Pares had to cope with as the Director of the School. The author concludes that Bernard Pares' role as a promoter of all things Russian, a translator of Russian poetry and prose, a researcher into Russian history and an organiser of Russian and Slavonic studies in Britain was indispensable.

Keywords: Bernard Pares; The Slavonic Review; Russian studies; University of London; British historiography; USSR. 